\title{
Convulsive Seizure Protection after Hippocampal Transplantation of Mesenchymal Cells from Adipose Tissue in Mice
}

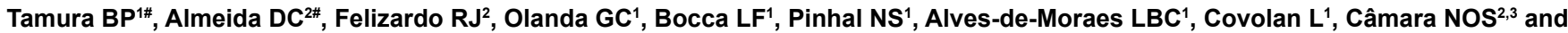 \\ Longo $\mathrm{BM}^{1 *}$
}

\#Authors contributed equally to this work

${ }^{1}$ Laboratory of Neurophysiology, Department of Neurophysiology, Federal University of São Paulo - UNIFESP - São Paulo, Brazil.

${ }^{2}$ Laboratory of Clinical and Experimental Immunology, Department of Medicine - Nephrology, UNIFESP - São Paulo, Brazil.

${ }^{3}$ Laboratory of Transplant Immunology, Department of Immunology, University of São Paulo - USP, Brazil

\begin{abstract}
A considerable number of epileptic patients had become resistant to antiepileptic drugs, justifying the need for development of new therapeutic strategies to treat epilepsy. The use of mesenchymal stem cells is an innovative and accessible strategy for the treatment of neuronal disorders, due to their involvement in immunoregulatory mechanisms, trophic and anti-apoptotic action.

Objective: Based on this evidence, we evaluated the protective effect of mesenchymal cells from adipose tissue (MCAT) by behavioral and inflammatory responses against convulsive seizure induced by maximum electroconvulsive shock (MES).

Methods: MCAT cells were transplanted into the hippocampus of adult male mice, and ten days after the transplantation MES stimulation was applied to induce a generalized tonic-clonic seizure. To evaluate the anticonvulsant activity of MCAT cells, we evaluated the parameters involved with: protection and reduction in the duration of tonic phase, reduction in the mortality rate, and alteration in the hippocampal gene expression of IL-1beta, IL-6, IL-4, IL-10, caspase-1, iNOS and TNFa.

Results: MCAT cells transplanted into the hippocampus altered the convulsive threshold, showed anticonvulsant effect by protecting from tonic seizures and mortality and reduced the hippocampal expression of transcripts related to inflammatory response such as IL-1beta, IL-6, caspase-1 and iNOS and increased the level of anti-inflammatory interleukin IL-4.

Conclusion: The anticonvulsant effects of the MCAT cells on acute convulsive seizure may be related to inhibitory factors and immunomodulatory mechanisms assigned to mesenchymal cells in the hippocampus. These anticonvulsants mechanisms of MCAT cells bring strong therapeutic implications for the control of epileptic seizures.
\end{abstract}

Keywords: Epilepsy; Maximum electroconvulsive shock; Hippocampus; Cell therapy; Mesenchymal cells from adipose tissue; Immunomodulatory mechanisms; Interleukins

\section{Introduction}

Treatments to control epileptic seizures are practically restricted to the use of antiepileptic drugs such as phenytoin, carbamazepine and oxcarbamazepine that present many secondary effects and are not totally effective in controlling the seizures. A considerable number of patients diagnosed with epilepsy had become resistant to these drug treatments. Moreover, epileptic seizure has been proposed as an inflammatory event, and that inflammatory mediators may contribute to the onset and recurrence of seizures [1]. In this context, it is essential to develop new therapeutic approaches for controlling or even suppressing the convulsive seizures through new research fronts, including the use of mesenchymal stem cell-based therapy.

An increasing number of studies have shown the therapeutic potential of stem cells obtained from various sources such as bone marrow, brain, umbilical cord blood, skin and adipose tissue, most of them proposed to be used in treatments of central nervous system diseases [2]. Mesenchymal stem cells (MSCs) present in the stroma of various vascularized organs represent one of the most studied populations of adult stem cells. Advantageously, these cells can be obtained from different tissues and expanded in vitro, as well as their trophic properties, make these cells excellent candidates for use in cellbased therapy [3]. Adipose tissue is an accessible source of progenitor mesenchymal cells that has been used to treat neurological diseases in a series of clinical trials $[4,5]$. It's widely believed that the protective mechanisms attributed to MSCs involve the secretion of substances engaged in anti-inflammatory, proliferative and anti-apoptotic response. These cells can rapidly migrate to ischemic sites [6,7] and infiltrate in the brain parenchyma, which may interact primarily with microglia or endothelial cells [8], as well as neurons and astrocytes $[9,10]$.

Experimental models of epilepsy have been developed as an attempt to expand knowledge of human epilepsy and develop more effective treatments. The maximum electroshock-induced seizure (MES) is a classical experimental model to induce generalized tonicclonic seizures in rodents. This model mimics seizures commonly found in drug-resistant patients, and is the chosen model for primary screening of new antiepileptic drugs $[11,12]$. The seizure induced by

*Corresponding author: Beatriz Monteiro Longo, Neurofisiologia, Depto. Fisiologia - UNIFESP- SP, R. Botucatu, 8625 andar, V. Clementino - São PauloSP, Brazil, Tel: (5511) 5579-2033; 5576-4513; E-mail: beatriz.longo@unifesp.br, beatrizlongo@gmail.com

Received March 01, 2014; Accepted April 16, 2014; Published April 18, 2014

Citation: Tamura BP, Almeida DC, Felizardo RJ, Olanda GC, Bocca LF, et al. (2014) Convulsive Seizure Protection after Hippocampal Transplantation of Mesenchymal Cells from Adipose Tissue in Mice. J Stem Cell Res Ther 4: 196. doi:10.4172/2157-7633.1000196

Copyright: (C) 2014 Tamura BP, et al. This is an open-access article distributed under the terms of the Creative Commons Attribution License, which permits unrestricted use, distribution, and reproduction in any medium, provided the original author and source are credited. 
MES generates a tonic flexion and extension behavior of the upper and / or lower limbs, followed by clonus. After the clonic and tonic phases, the animal shows loss of postural reflex followed by a period of post-ictal depression whose duration depends on the intensity of stimulation [13]. The screening tests evaluate the treatment ability in preventing the seizure activity across the neuronal tissue, which is indicated by blocking or reducing mainly the tonic component of generalized seizures $[14,15]$. Interestingly, the induction of MES has been implicated in alterations in cytokines gene expression, which indicates a commitment of inflammatory responses to the convulsive stimulus [16,17].

Based on these evidences, we propose to test the hypothesis that mesenchymal cells from adipose tissue (MCAT) transplanted in the hippocampus may have anticonvulsant effects on the behavioral and immunomodulatory mechanisms leading to a protection against tonic seizures and reduction of animal mortality induced by the MES model and in the pro-inflammatory cytokine levels, as well as an induction of anti-inflammatory responses. Thus, this study investigated the protective effect offered by the MCAT cells against acute epileptic seizures.

\section{Methods}

\section{Subjects}

Subjects were C57BL/6 and transgenic C57BL/6 expressing EGFP (enhanced green fluorescent protein) male mice, aged 8-12 weeks at the beginning of the experiments. They were housed in a pathogenfree facility and maintained in accordance with the Guide for the Care and Use of Laboratory Animals (National Research Council), in groups of 3-5 in polypropylene cages $(28 \times 17 \times 13 \mathrm{~cm})$ with wood shavings on the floor, under standard laboratory conditions, having free access to food and water. Room temperature was kept at $21^{\circ} \mathrm{C} \pm 1{ }^{\circ} \mathrm{C}$ and lights (50 lux) were on at 07:00 h and off at 19:00 h. All protocols were approved by the Ethics Committee of the Universidade Federal de São Paulo (UNIFESP), process 145/10 under approval of the National Commission of Ethics in Research (CONEP/MS).

\section{Isolation and preparation of mesenchymal stem cells from adipose tissue (MCAT)}

MCAT cells were isolated from C57/B6 mice by enzymatic digestion (collagenase type 1A) of the supra-epididymal and subjected to the process of culture with DMEN Low (Dulbecco's Modified Eagle's Medium Low) supplemented with 10\% fetal calf serum (FCS). The MCAT was characterized by morphology and multipotent potential conforming described in Bassi and co-authors [18]. Subsequently, the cells were expanded, characterized in vitro to confirm their mesenchymal nature, and transplanted when they reached approximately $80 \%$ confluence in culture.

\section{Cell transplantation of the mesenchymal cells from adipose tissue (MCAT)}

After grown in culture, MCAT were labeled with the fluorochrome PKH26 (Sigma Aldrich) by incubation for $30 \mathrm{~min}$ immediately before transplantation. Then, MCAT cells were bilaterally transplanted in mice (MCAT, $\mathrm{n}=12$ ) by stereotaxic surgery, $1 \times 10^{5}$ cells into the hippocampus $(50,000$ per hemisphere). The stereotaxic coordinates used for the MCAT transplantation have the bregma as a reference and these are: $-2.0 \mathrm{~mm}$ in the antero-posterior, $-1.5 \mathrm{~mm}$ and +1.5 $\mathrm{mm}$ in medial-lateral for both sides, and $-2.5 \mathrm{~mm}$ dorso-ventral directions [19]. The cell infusion was performed by injecting cells in culture medium suspension with a Hamilton syringe $(10 \mu \mathrm{L})$ at a rate of $1 \mathrm{uL} / 15$ seconds in order to avoid embolism by mesenchymal cells in the hippocampus or adjacent structures. The injection canullae was removed one minute after the inoculation. The same procedure was performed for the control group (CTRL, $n=12$ ), injecting the same volume of culture medium in the same points.

\section{Convulsive seizure induction by maximum electroshock seizure model (MES)}

Between seven and ten days after the transplantation surgery, the group of transplanted mice (MCAT-MES group, $n=12$ ) and the group that received only the culture medium (CTRL-MES group, $\mathrm{n}=12$ ) underwent maximum electroshock seizure (MES), which is an electroshock stimulus ( $65 \mathrm{~mA}, 60 \mathrm{~Hz}, 0.15 \mathrm{~s}$ duration) applied via transcorneal to induced the tonic-clonic seizure. The procedure was performed for 5 consecutive days, at the same time of the day, due to their circadian cycles. The evaluated parameters to verify a possible protection against seizures were visual monitored and quantified for the presence or absence of individual components of the tonicclonic frequency, the duration of each phase, including the post-ictal phase, and the mortality rate. The pattern and frequency of seizures were evaluated and quantified according to the scale of Racine for classification of seizures (1972) and compared between groups. We evaluated the occurrence, duration and intensity of each tonic/clonic component of seizure [12]. The parameters considered to estimate the anticonvulsant activity of the cells were the protection against leg extension and reduction of the duration of tonic seizure [11].

\section{Immunohistochemistry}

Five days after the MES, the animals were deeply anesthetized with $10 \%$ chloral hydrate and transcardiacally perfused with 50 $\mathrm{mL}$ of phosphate buffered saline (PBS) followed by $250 \mathrm{~mL}$ of $4 \%$ paraformaldehyde. The brains were dissected and coronal brain cryostat sections ( $35-\mu \mathrm{m}$ thick) were made between bregma +1.10 and $-3.08 \mathrm{~mm}$, according to the stereotaxic coordinates of the mouse brain atlas [15]. Because MCAT cells were already labeled with fluorochrome $\mathrm{PKH} 26$, the cells were identified by fluorescence microscopy directly under the Nikon 80i, filter (red), and it was not used any specific antibody to visualize the transplanted cells in the hippocampus. The slices were incubated with three distinct markers, chosen to verify the phenotype of neurons (NeuN), astrocytes (GFAP) and microglia (Iba1), and used separately. The NeuN (1:2000), GFAP (1:2000) and Ibal primary antibodies were made in rabbit, and all were combined with a secondary anti-rabbit Alexa-fluor488. All of the slides stained with these markers were examined using a fluorescence microscopy (Nikon 80i). In each section, double-labeled cells were searched for the presence of MCAT cells expressing these specific markers and their localization in the hippocampus. Sections were mounted on slides using a nuclear-counterstaining, fluorescence-preserving mounting medium containing DAPI (Vector).

For DCX immunohistochemistry, free-floating sections were incubated overnight with the primary antibody DCX (1:500) diluted in PBS. After incubation, the sections were washed in PBS and incubated with the $\mathrm{ABC}$ kit solutions (Vectashield, Vector, Burlingame, CA, USA) for $1.5 \mathrm{~h}$. The sections were stained with diaminobenzidine (DAB, Sigma-Aldrich Corporation, St. Louis, USA) and mounted on gelatin-coated slides and coverslipped. Images were captured and digitized using the Nikon ACT-1 v.2 system. 


\section{Histological analysis}

The qualitative analysis was performed by immunofluorescence for $\mathrm{Ibal}^{+}$cells for morphological characteristics of microglia. The quantification of DCX positive cells was performed by light microscopy (Nikon 80i). The images were captured and digitised using the Nikon ACT-1 v.2 system and analysed with the Image J software. Four dorsal hippocampal slices per animal (4 slices for each marker) and an average of eight non-overlapping fields per slice, totalling 32 fields per hippocampus for each animal were analysed at 40x magnification. In each section, nuclear profiles of DCX were counted by an observer blind to the experimental condition.

\section{Gene expression}

Fresh hippocampal samples were collected to quantify the expression of IL-1 $\beta$, IL-6, IL-4, IL-10, TNF- $\alpha$, caspase-1 and iNOS genes. Total RNA was extracted using TRIzol' reagent (Life Technologies, USA), and isopropanol precipitation. After RNA isolation, the concentration was made using a Nanodrop spectrophotometer (Thermo Scientific, USA). The mRNA was reversely transcribed using the High Capacity kit (Life Technologies, USA), and primed with Oligo dT. The expression level of each evaluated gene was measured by qPCR using the TaqMan system (Life Technologies, USA) and the equipment ABI Prism 7300 (Life Technologies, USA). The endogenous HPRT gene was used to normalization. The amplification program was as it follows: $50^{\circ} \mathrm{C}$ for 2 min, $95^{\circ} \mathrm{C}$ for $10 \mathrm{~min}$, followed by 40 cycles of $95^{\circ} \mathrm{C}$ for 30 seconds and $60^{\circ} \mathrm{C}$ for 1 minute. The results were analyzed through the URE method of relative quantification $\left(10,000 / 2^{\wedge} \Delta \mathrm{Ct}\right)$ using the SDS software (Life Technologies, USA).

\section{Statistics}

Statistical analyses were performed using Prism software (version 288 5.01, GraphPad Software, San Diego, CA, USA). Convulsive seizure behavior, cell quantification and PCR gene expression were analyzed with Student $t$-test Data are presented as the mean \pm S.E.M. Differences were considered significant when $\mathrm{p}<0.05$.

\section{Results}

\section{Behavioral seizure analysis}

In order to verify the potential of modulation of these cells in repetitive intense stimulus, the seizures induced by MES were applied starting 10 days after transplantation of MCAT or DMEM (CTRL) during 5 consecutive days (named as day 1 , day 2, day 3 , day 4 , day 5). The seizures were analyzed in each day from the $1^{\text {st }}$ to the $5^{\text {th }}$ day comparing both groups, CTRL-MES and MCAT-MES, for the frequency and duration of each phase, including the post-ictal phase, and the total mortality rate of the 5 days.

All animals (100\%) presented clonic seizures in all of the 5 days. At the $1^{\text {st }}$ day, $90 \%$ of CTRL-MES and $100 \%$ of MCAT-MES groups presented tonic seizures. At day 2, 85\% of CTRL and 100\% of MCAT groups presented tonic seizures. In the subsequent days (day 3, 4 and 5), $100 \%$ from both CTRL-MES and MCAT-MES presented tonic seizures. When comparing these data, no difference was found in the frequency of animals presenting seizures between the two groups.

The analysis of the duration (sec) of tonic seizure showed a decrease of time period on the MCAT transplanted animals on day 3, day 4 and day 5 compared with CTRL-MES group (respectively $\mathrm{p}=0.0045 ; \mathrm{p}=0.0472 ; \mathrm{p}=0.0272$ ), indicating a long-term protective action of MCAT-MES, with an initial delay for this modulation (Figure 1A-1C). Additionally, it was observed a significant reduction in the duration of the post-ictal phase in the MCAT transplanted group ( $\mathrm{p}=0.0128$ ), indicating faster recovery after the convulsion, which is also an indicative of protection. The duration of clonic seizures was significantly increased in MCAT-MES when compared to the CTRLMES group ( 5 days average $p=0.0007$ and $p<0.01$ for each day; Figures $1 \mathrm{D}$ and $1 \mathrm{E})$ suggesting that the generalized seizure had to manifest itself somehow, but protection of tonic phase induced increased in seizure manifested as clonia. The differences between the times of tonic and clonic seizures within the same group implied that the total time of generalized seizures was not different between the groups.

Interestingly, the mortality rate was reduced in the MCAT-MES transplanted animals when compared with CTRL-MES group (Chisquare $\mathrm{p}<0.0001$ ). The protection in mortality of MCAT animals was probably related to the reduction in time of tonic seizures observed in this group (Figure 1F).

\section{Hippocampal immunochemistry}

A qualitative analysis in the host hippocampus of animals transplanted with MCAT cells was performed by immunofluorescence to confirm the presence, localization into the hippocampal regions and expression of neuronal, astrocyte and microglial markers (NeuN, GFAP and Iba1). The presence of MCAT cells in the hippocampus was confirmed in all transplanted animals and most of the MCAT cells were found preferentially at dentate gyrus (DG). This finding indicated that MCAT transplanted cells had survived after the application of MES for 5 days. The MCAT cells were detected in clusters, closely associated to the site of injection (DG), and also found scattered in the path of the needle (Figures $2 \mathrm{~A}$ and $2 \mathrm{~B}$ ).

Some MCAT cells double-stained for Ibal marker were detected, and high concentration of resident microglial expressing Iba1 was present at the site of injection (DG), surrounding the MCAT transplanted cells (Figures 3A-3C). No MCAT cells expressing NeuN and GFAP markers were detected in the hippocampus (Figures 3D-3I). Quantification of DCX positive cells was done in the hippocampus, and did not differ between CTRL-MES and MCAT-MES groups (Figures $4 \mathrm{~A}-4 \mathrm{C})$.

\section{Cytokine gene expression analysis}

To investigate the immunomodulatory mechanisms by which the MCAT therapy resulted in tonic seizure protection, we tested whether the transplantation of MCAT cells modulates the hippocampal gene expression of Il-1 $\beta$, IL-6, IL-4, IL-10, iNOS, caspase- 1 and TNF- $\alpha$. The results indicated that the levels of IL- $1 \beta$ and IL- 6 in MCAT-MES group decreased compared to CTRL-MES (Student $t$ test, $p=0.0266$ and $\mathrm{p}=0.0206$, Figures $5 \mathrm{~A}$ and $5 \mathrm{~B}$ ). In addition, the transplantation of MCAT cells also reduced levels of iNOS and caspase- 1 in the hippocampus ( $p=0.0405$ and $p=0.0034$, Figures $5 \mathrm{C}$ and $5 \mathrm{D})$. The antiinflammatory cytokine IL-4, we detected increased in MCAT-MES group than CTRL-MES ( $\mathrm{p}=0.0025$, Figure 5E). The levels of IL-10 and TNF- $\alpha$ in the hippocampus did not differ significantly between the groups (data not shown).

\section{Discussion}

Our findings indicated that MCAT cells transplanted into the hippocampus exert anticonvulsant effects by blocking the tonic component of generalized seizures and reducing the mortality rate 
A
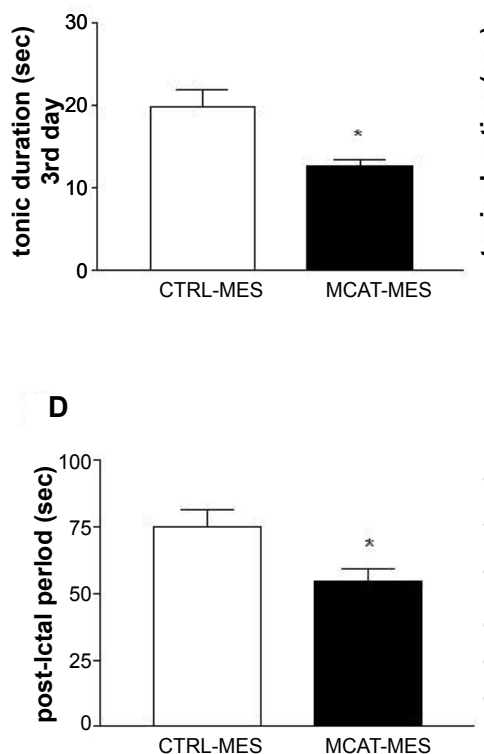

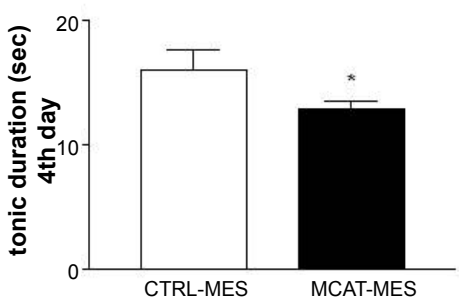

E

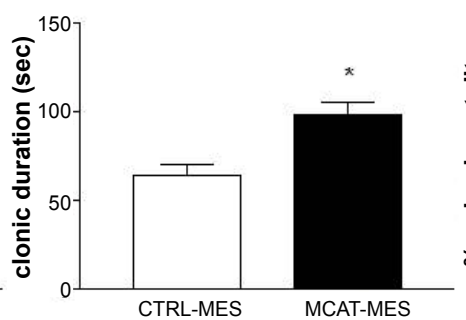

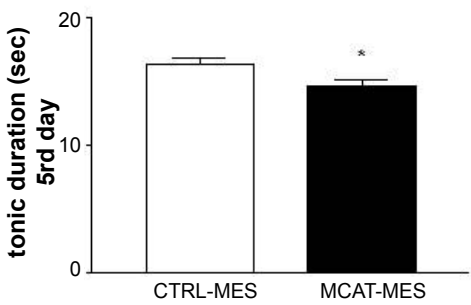

$\mathbf{F}$

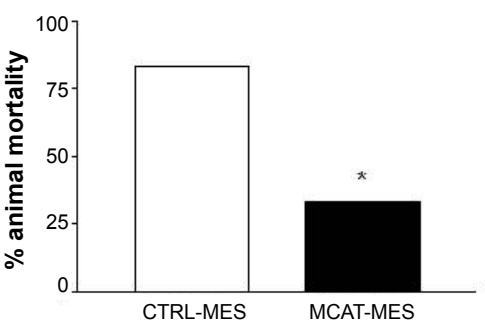

Figure 1: Evaluated parameters in seizures induced by MES. Analysis of tonic duration indicated a reduction in day 3 (A), day 4 (B) and day 5 (C) of MES stimulation for the MCAT-MES group $(n=12)$ when compared to the CTRL-MES group $(n=12)$; D) The duration of post-ictal period also decreased in MCAT-MES group; E) Clonic seizures after MES stimulation comparing CTRL-MES and MCAT-MES groups indicated an increase in MCAT-MES; and F) percentage of mortality rate shows considerable reduction in of MCAT-MES group compared to CTRL-MES group ( ${ }^{*} \mathrm{p}<0.05$, Student $t$ test; in $\mathrm{F}$ Chi-square). From A to E, data represented by mean \pm S.E.P.
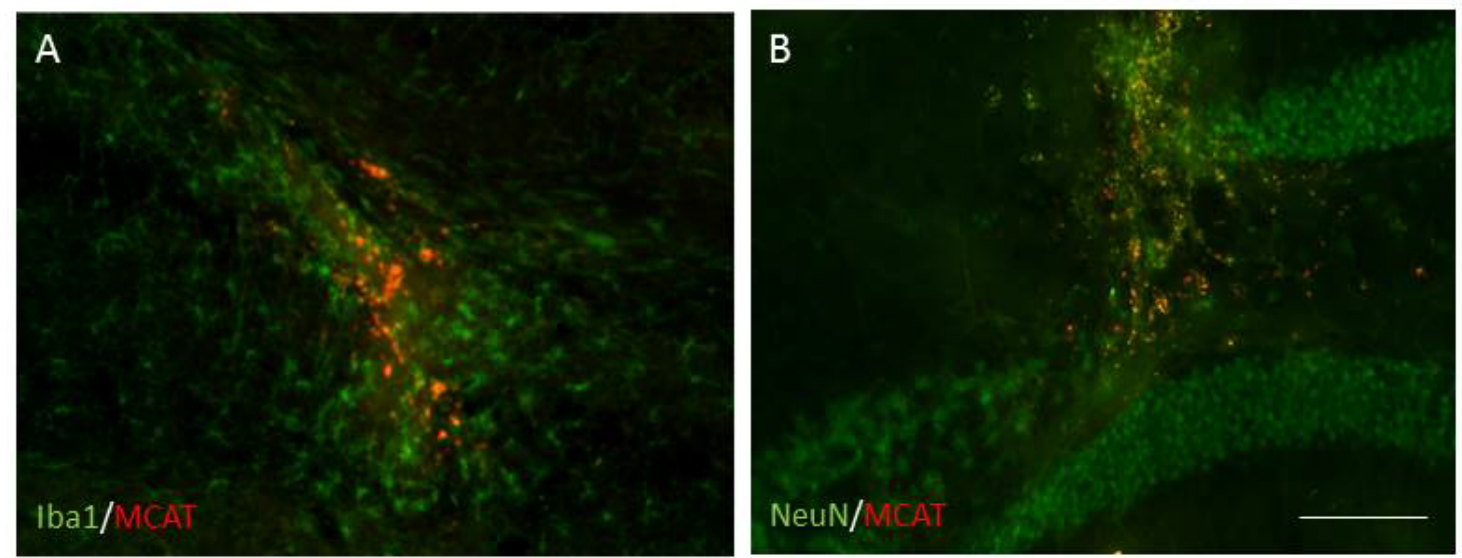

Figure 2: Images from fluorescence microscopy showing MCAT cells stained with fluorochrome PKH26 in the hippocampus. A) MCAT cells survived after the application of MES for 5 days and were detected in clusters in MCAT-MES transplanted mice; B) MCAT cells close to the site of injection (DG), and also found scattered in the path of the needle MCAT-MES. Scale bar $100 \mu \mathrm{m}$.

induced by MES. In addition, the seizures in MCAT-transplanted mice triggered an acute inflammatory response, changing the pattern of IL1- $\beta$, IL-6, iNOS, caspase-1 and IL-4 gene expression. The immunofluorescence analyses confirmed the presence of MCAT cells in the hippocampus of transplanted animals and the co-localization of MCAT cells and neural marker was not detected. The immunomodulatory and anti-inflammatory properties of mesenchymal cells are well known and have been emerging as a new therapeutic alternative for a wide variety of degenerative and immune disorders. Based on our findings, we questioned whether the MCAT cells, when transplanted into the hippocampus, could have a local action that would influence the neuronal activity in the hippocampus by modulating the excessive and synchronous neuronal firings that result in seizures, or acting by releasing modulatory substances which could "turn off" the tonic activity of generalized seizures.

Browning and colleagues suggested that generalized seizures have distinct neuroanatomical substrates that start and sustain the seizure activity [20]. It is possible that the site of injection of the mesenchymal cells (hippocampus) has influenced the weakening of convulsive behavior of transplanted animals. The hippocampus, as already well described, plays an important role in triggering and amplifying 
Citation: Tamura BP, Almeida DC, Felizardo RJ, Olanda GC, Bocca LF, et al. (2014) Convulsive Seizure Protection after Hippocampal Transplantation of Mesenchymal Cells from Adipose Tissue in Mice. J Stem Cell Res Ther 4: 196. doi:10.4172/2157-7633.1000196
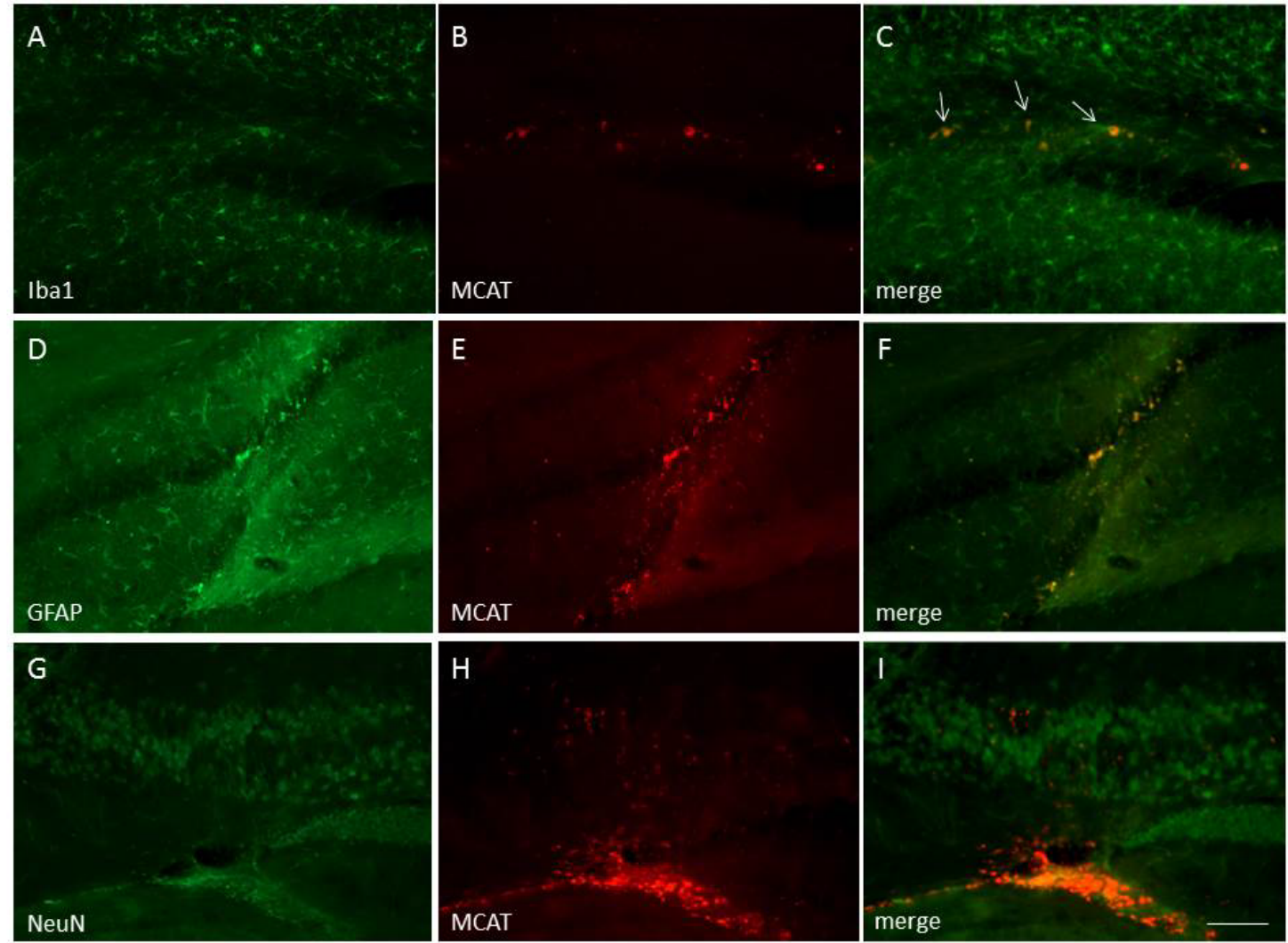

Figure 3: MCAT cells (red) and NeuN, GFAP and Iba1 markers (green) in the hippocampus. A) Iba1 ${ }^{+}$cells (green) present at the site of injection (DG), surrounding the MCAT transplanted cells (B); In C) note the microglia phenotype of MCAT cells (arrows) in the dentate gyrus (DG). D-I) No co-localization of MCAT cells (red) with GFAP and NeuN markers (green) in the hippocampus. Scale bar $100 \mu \mathrm{m}$.
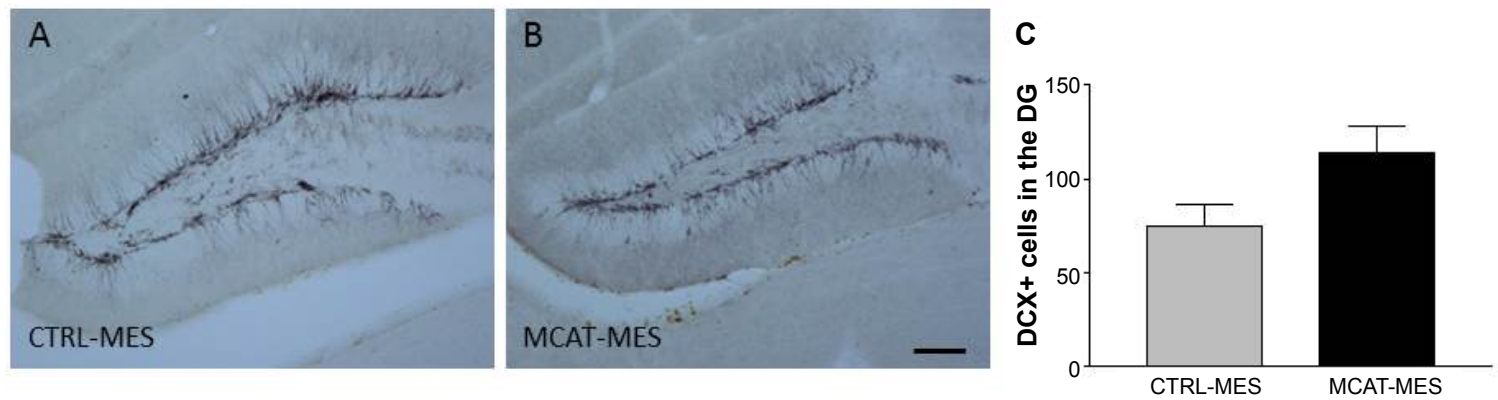

Figure 4: Doublecortin (DCX) images and quantification in the hippocampus of CTRL-MES and MCAT-MES groups. A) DCX in the dentate gyrus (DG) of a CTRL-MES mouse and B) MCAT-MES mouse; in C) no difference was found in the number of DCX+ cells counted in the DG between CTRL-MES and MCAT-MES groups. In $A$ and $B$ scale bar $50 \mu \mathrm{m}$. In $\mathrm{C}$ data represented by mean \pm S.E.P.

epileptic seizures. This structure might lose or diminish the potential of inducing seizures, since the mesenchymal cells have been injected into the dentate gyrus. In this case, one possible reason to explain the protection effect is that the transplanted cells showed a barrier effect, preventing the hyperexcitability in the local circuit and avoiding the spread (generalization) of seizures, expressed by reduction in duration (tonic) and in post-ictal period. Interestingly, in these transplanted animals the duration of clonic seizures increased as a compensatory effect of the inhibition of tonic seizure, as if the generalized seizure had to manifest itself somehow.
The hippocampus, a structure susceptible to convulsive seizures [21,22] contains cells vulnerable to electroshock [23-25]. In fact, the stimulus of the electrochock, regardless the MCAT treatment, induced an increased in the hippocampal neurogenesis and neuronal death. The presence of MCAT cells in the hippocampus could just be a mechanism induced by the cells to replace cells in this area (known for its susceptibility to neuronal loss), rather than a direct effect to protect seizures. However, MCAT cells were not co-localized with neural markers and quantification of DCX did not differ between S-MES and MCAT-MES animals. 
A

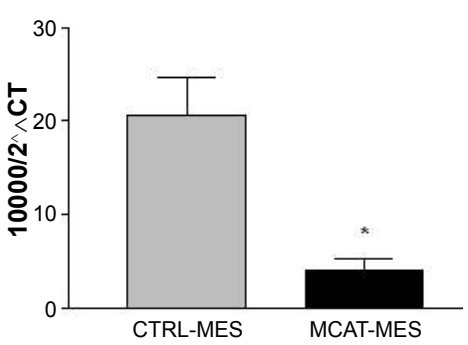

B

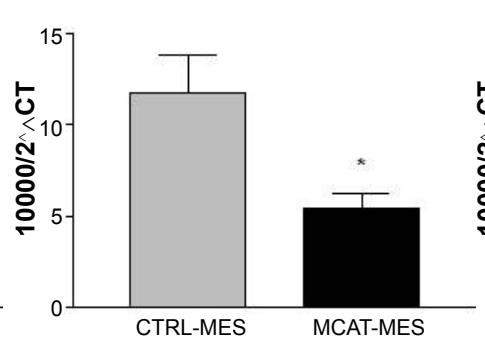

C

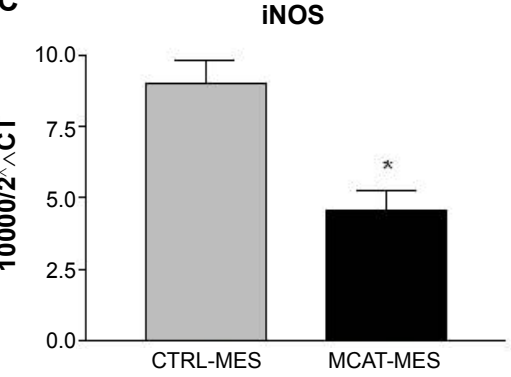

D

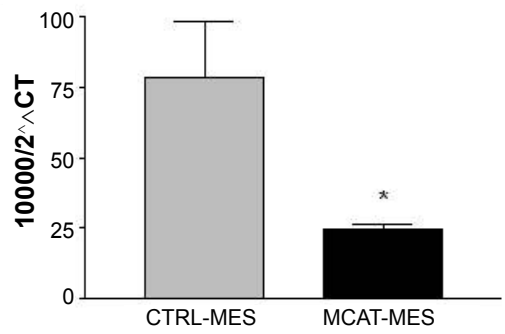

E

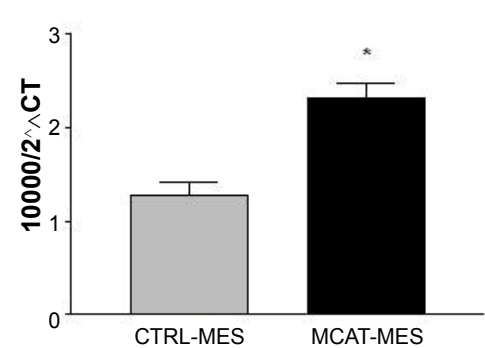

Figure 5: Hippocampal gene expression of II-1 $\beta$, IL-6, iNOS, caspase-1 and IL-4. In A) IL-1 $\beta$; in B) IL-6; in C) iNOS and in D) caspase-1 dosed in the hippocampus of MCAT-MES group showed a decreased compared to CTRL-MES; in E) IL-4 showed an increased in MCAT-MES group compared to CTRL-MES ( ${ }^{*} p<0.05$, Student $\mathrm{t}$ test). Data represented by mean \pm S.E.P.

As already described, microglial cells present morphological alterations after maximum electroconvulsive shock (MES) [16,17,26]. These authors described a reduction in the density of microglial processes after MES, which is indicative of an intermediate stage between inactive and reactive microglia $[27,28]$. We noticed that part of the MCAT population expressed the microglial marker Ibal and developed microglia phenotype. Also, our results corroborate others that described an increase in $\mathrm{Iba1}^{+}$cells around the transplanted mesenchymal cells in the hippocampus of rats with Alzheimer's disease [29]. As proposed by Silverberg and co-authors, inflammatory cells are recruited to regions of the brain associated with the epileptic focus [30]. These authors suggested that in MES-induced seizures, electric currents spread throughout the brain and the intensity and/ or duration of stimulation can change the levels of cytokines and chemokines. Nevertheless, is still unclear whether Iba $1^{+}$cells present in the hippocampus play a role on generalized or focal seizures and/or directly participate on clonic seizures that persist.

As suggested by Jankowski and Patterson [28], the beginning and duration of seizure are influenced by a variety of types and levels of cytokines that, at the time of induction, can compete to determine the behavioral outcome. Several studies have reported the high concentration of IL- 6 immediately after the seizure [31,32]. Moreover, the proconvulsant effects of IL- $1 \beta$ have been proposed since its levels in the brain increased during seizures [33]. Interestingly, the inhibition caspase-1, which is involved in the production of the active form of IL$1 \beta$ and plays a role reducing the brain levels of IL- $1 \beta$, has been suggested as an effective anticonvulsive strategy [34]. In our experiment, the gene expression of IL1- $\beta$, IL-6, caspase- 1 and iNOS was significantly lower in animals transplanted with MCAT. This reduction in proinflammatory cytokines as well as caspase- 1 and iNOS can be related to the reduction of tonic seizure in the MCAT-MES group. Together with this reduction, the expression of anti-inflamatory cytokine IL-4 was increased in the MCAT transplanted animals, which may have reduced the susceptibility to seizure-induced pro-inflammatory cytokines. Although increase in IL-10 was not detected, our data corroborate other findings that showed a reduction of pro-inflammatory and increase of anti-inflammatory cytokines in chronic epileptic rats treated with bone marrow cells [35]. Similarly, other authors proposed that the expression of IL-10 can be induced simultaneously with proinflammatory cytokines in brain after an insult $[36,37]$. The beneficial or harmful role of the innate immune response in epileptic tissue, however, still needs to be clarified [38].

Taken together, our results suggest that the protective effects of MCAT cells are possibly promoted by the action of inhibitory factors and immunomodulatory mechanisms assigned to mesenchymal cells on seizure spreading. Moreover, we suggest that the anticonvulsant potential of MCAT cells can be tested by MES model, using the same paradigm used in pharmacological screening tests of drugs. Taking this contribution into account, several considerations concerning the MCAT cells, neuro-regulatory molecules and cytokines secretion, as well as growth factors that mediate the protective effects on convulsive seizure should be elucidated by further experiments. This study brings therapeutic implications for the control of epileptic seizures and may open interesting discussions on the mechanisms relevant to the pathophysiology of epilepsy.

\section{Acknowledgments}

We are grateful to Emanuel Barreto and Marcos Antonio Cenedeze for the technical support. This work was supported by FAPESP and CNPq.

\section{References}

1. Vezzani A, Balosso S, Maroso M, Zardoni D, Noé F, et al. (2010) ICE/caspase 1 inhibitors and IL-1beta receptor antagonists as potential therapeutics in epilepsy. Curr Opin Investig Drugs 11: 43-50.[PubMed] 
Citation: Tamura BP, Almeida DC, Felizardo RJ, Olanda GC, Bocca LF, et al. (2014) Convulsive Seizure Protection after Hippocampal Transplantation of Mesenchymal Cells from Adipose Tissue in Mice. J Stem Cell Res Ther 4: 196. doi:10.4172/2157-7633.1000196

2. Mello LE, Longo, BM (2010) Neurogenesis: A change of paradigms. In: H Ulrich (Ed.), Perspectives of stem cells: from tools for studying mechanisms of neuronal differentiation towards therapy, Springer.

3. Brazelton TR, Adams B, Shorthouse R, Morris RE (1999) Chronic rejection: the result of uncontrolled remodelling of graft tissue by recipient mesenchymal cells? Data from two rodent models and the effects of immunosuppressive therapies. Inflamm Res 48: S134-S135.[PubMed]

4. Caplan A (2006) Lies in embryo. Free Inq 26: 15-16.[PubMed]

5. Crigler L, Robey RC, Asawachaicharn A, Gaupp D, Phinney DG (2006) Human mesenchymal stem cell subpopulations express a variety of neuro-regulatory molecules and promote neuronal cell survival and neuritogenesis. Experimental Neurology 198: 54-64.[PubMed]

6. Majka SM, Jackson KA, Kienstra KA, Majesky MW, Goodell MA, et al. (2003) Distinct progenitor populations in skeletal muscle are bone marrow derived and exhibit different cell fates during vascular regeneration. J Clin Invest 111(1): 71-79.[PubMed]

7. Rafii S, Lyden D (2003) Therapeutic stem and progenitor cell transplantation for organ vascularization and regeneration. Nat Med 9(6): 702-712.[PubMed]

8. Zhang GX, Li J, Ventura E, Rostami A (2002) Parenchymal microglia of naïve adult C57BL/6J mice express high levels of B7.1, B7.2, and MHC class II. Exp Mol Pathol 73: 35-45.[PubMed]

9. Eglitis MA, Dawson D, Park KW, Mouradian MM (1999) Targeting of marrowderived astrocytes to the ischemic brain. Neuroreport 10: 1289-1292.[PubMed]

10. Chen J, Sanberg PR, Li Y, Wang L, Lu M, et al. (2001) Intravenous administration of human umbilical cord blood reduces behavioral deficits after stroke in rats. Stroke 32: 2682-2688.[PubMed]

11. Browning DK, Nelson (1985) Variation in threshold and pattern of electroshockinduced seizures in rats depending on site of stimulation. Life Sciences 37 : 2205-2211.[PubMed]

12. Swinyard EA, Brown WC, Goodman LS (1952) Comparative assays of antiepileptic drugs in mice and rats. J Pharmacol Exp Ther 106(3): 319-330. [PubMed]

13. Mares P, Kubová H (2006) Electrical Stimulation - Induced Models of Seizures. In: Pitkänem A, Schwartzkroin PA, Morshé S. (Ed.). Models of Seizures and Epilepsy. California: Elsevier.

14. Loscher, D Honack, B Nolting, CP, Fassbender (1991) Trans-2-en-valproate: reevaluation of its anticonvulsant efficacy in standardized seizure models in mice, rats and dogs. Epilepsy Research 9(3): 195-210.[PubMed]

15. Swinyard EA, Woodhead JH, Franklin MR, Sofia RD, Kupferberg HJ (1987) The effect of chronic felbamate administration on anticonvulsant activity and hepatic drug-metabolizing enzymes in mice and rats. Epilepsia 28: 295-300. [PubMed]

16. Jansson L, Wennstrom M, Johanson A, Tingstrom A (2009) Glial cell activation in response to electroconvulsive seizures. Prog Neuropsychopharmacol Biol Psychiatry 33: 1119-1128.[PubMed]

17. Jinno S, Kosaka T (2008) Reduction of Iba1-expressing microglial process density in the hippocampus following electroconvulsive shock. Exp Neurol 212 440-447.[PubMed]

18. Bassi EJ, Moraes-Vieira PM, Moreira-Sá CS, Almeida DC, Vieira LM, et al. (2012) Immune regulatory properties of allogeneic adipose-derived mesenchymal stem cells in the treatment of experimental autoimmune diabetes. Diabetes 61: 2534-2545.[PubMed]

19. Paxinos G (2003) The Mouse Brain in Stereotaxic Coordinates, second edition ed. Academic Press.
20. Browning RA (1999) Effect of precollicular transection on audiogenic seizures in genetically epilepsy-prone rats. Exp Neurol 155: 295-301.[PubMed]

21. Loscher W, Ebert U (1996) Basic mechanisms of seizure propagation: targets for rational drug design and rational polypharmacy. Epilepsy Res Suppl 11 17-43.[PubMed]

22. Scharfman HE (2000) Epileptogenesis in the parahippocampal region. Parallels with the dentate gyrus. Ann N Y Acad Sci 911: 305-327.[PubMed]

23. Cardoso A, Assunção M, Andrade JP, Pereira PA, Madeira MD, et al. (2008) Loss of synapses in the entorhinal-dentate gyrus pathway following repeated induction of electroshock seizures in the rat. J Neurosci Res 86: 71-83. [PubMed]

24. Lukoyanov NV, Sa MJ, Madeira MD, Paula-Barbosa MM (2004) Selective loss of hilar neurons and impairment of initial learning in rats after repeated administration of electroconvulsive shock seizures. Exp Brain Res 154: 192200.[PubMed]

25. Zarubenko, II, Yakovlev AA, Stepanichev MY, Gulyaeva NV (2005) Electroconvulsive shock induces neuron death in the mouse hippocampus: correlation of neurodegeneration with convulsive activity. Neurosci Behav Physiol 35: 715-721.[PubMed]

26. Ferrazoli EG, Blanco MM, Bittencourt S, Bachi AL, Bahia L, et al. (2013) Anticonvulsant activity of bone marrow cells in electroconvulsive seizures in mice. BMC Neurosci 14: 97.[PubMed]

27. Streit WJ, Walter SA, Pennell NA (1999) Reactive microgliosis. Prog Neurobio 57(6): 563-581.[PubMed]

28. Jankowsky JL, Patterson PH (2001) The role of cytokines and growth factors in seizures and their sequelae. Prog Neurobiol 63: 125-149.[PubMed]

29. Lee JK, Jin HK, Bae JS (2009) Bone marrow-derived mesenchymal stem cells reduce brain amyloid-beta deposition and accelerate the activation of microglia in an acutely induced Alzheimer's disease mouse model. Neurosci Lett 450 136-141.[PubMed]

30. Silverberg J, Ginsburg D, Orman R, Amassian V, Durkin HG, et al. (2010) Lymphocyte infiltration of neocortex and hippocampus after a single brief seizure in mice. Brain Behav Immun 24: 263-272.[PubMed]

31. Li G, Bauer S, Nowak M, Norwood B, Tackenberg B, et al. (2011) Cytokines and epilepsy. Seizure 20: 249-256.[PubMed]

32. Peltola J, Hurme M, Miettinen A, Keranen T (1998) Elevated levels of interleukin-6 may occur in cerebrospinal fluid from patients with recent epileptic seizures. Epilepsy Research 31: 129-133.[PubMed]

33. Dube C, Vezzani A, Behrens M, Bartfai T, Baram TZ (2005) Interleukin-1beta contributes to the generation of experimental febrile seizures. Ann Neurol 57 152-155.[PubMed]

34. Ravizza T, Lucas SM, Balosso S, Bernardino L, Ku G, et al. (2006) Inactivation of caspase-1 in rodent brain: a novel anticonvulsive strategy. Epilepsia 47 1160-1168.[PubMed]

35. Costa-Ferro ZS, Souza BS, Leal MM, Kaneto CM, Azevedo CM, et al. (2011) Transplantation of bone marrow mononuclear cells decreases seizure incidence, mitigates neuronal loss and modulates pro-inflammatory cytokine production in epileptic rats. Neurobiol Dis 46: 302-313.[PubMed]

36. Kubera M, Budziszewska B, Basta-Kaiml A, Zajicova A, Holan V, et al. (2001) Immunoreactivity in kainate model of epilepsy. Polish Journal of Pharmacology 53: 541-545.[PubMed]

37. Zhai QH, Futrell N, Chen FJ (1997) Gene expression of IL-10 in relationship to TNF-alpha, IL-1 beta and IL-2 in the rat brain following middle cerebral artery occlusion. J Neurological Sciences 152: 119-124.[PubMed]

38. Vezzani A (2005) Inflammation and epilepsy. Epilepsy Curr 5: 1-6.[PubMed] 